\title{
Polycythaemia Rubra Vera: A Case Report \& Review of Literature
}

\author{
M. MAKSUMUL HAQ ${ }^{1}$, SAHELA NASRIN ${ }^{1}$, SYED DAWOOD MD. TAIMUR ${ }^{1}$, HEMANTA I GOMES ${ }^{1}$, MOHAMMAD \\ ARIFUR RAHMAN ${ }^{1}$ \\ Ibrahim Cardiac Hospital \& Research Institute, Dhaka
}

Address for correspondence: Dr. Shahela Nasrin , Department of Cardiology, Ibrahim Cardiac Hospital \& Research Institute , Shahbag, Dhaka.E-mail: sdmtaimur@yahoo.com

\begin{abstract}
:
We report a case of 73 year old woman with known risk factor (hypertension) for cerebrovascular disease who developed a TIA like symptom \& vertigo with spontaneous clinical improvement. CT showed left cerebral infarct. Haematological test revealed PRV. Clinical improvement was associated with a reduction in haematocrit levels. Hydroxyurea appears to be the least leukemogenic myelosuppressive agent in long term prospective clinical PRV studies extending observation period of $>10$ years. Low dose aspirin will prevent the microvascular thrombotic complications of thrombocythaemia associated with PRV in remission after phlebotomy.
\end{abstract}

Key words: Polycythaemia Rubra Vera(PRV);Thrombosis; Ischemic stroke

\section{Introduction:}

The incidence of thrombosis in people with Polycythaemia Rubra Vera ranges from 4 to 11.4 events/100 patients per year, as reported by the few prospective studies. ${ }^{1,2}$ In addition, the rate of thrombosis strongly depend on age \& previous thrombotic events. ${ }^{3-6}$ Haematological disorders account for up to $8 \%$ of all ischaemic strokes in different series.Primary polycythaemia, often called polycythaemia vera (PCV), polycythaemia rubra vera (PRV) or erythraemia, occurs when excess red blood cells are produced as a result of an abnormality of the bone marrow. ${ }^{7}$ Often excess white blood cells \& platelets are also produced. PRV is classified as a myeloproliferative disease.

Symptoms include headaches, vertigo \& an abnormally enlarged spleen (70\%) \& or liver (50\% cases). In some cases affected individual may have associated conditions including high blood pressure or the formation of blood clots. Patients often present with either arterial or venous vascular occlusive events. Coronary or cerebral events are prominent. PRV may lead to cerebrovascular occlusion, with effects ranging from TIA to irreversible stroke \& death. ${ }^{8}$ Transformation to acute leukemia is rare. Phlebotomy is the main stay of treatment. A hallmark of polycythemia is an elevated hematocrit, with hematocrit $>55 \%$ seen in $83 \%$ of cases. ${ }^{9}$

We report a case of PRV presented to us with high blood pressure, vertigo, TIA like symptoms \& raised hematocrit.

\section{Case report:}

Mrs Rafia Khatoon, 73 years old, hypertensive, dyslipidaemic, nondiabetic, Bangladeshi lady admitted with complaints of vertigo, uncontrolled blood pressure, intermittent weakness of right lower limb for two days. On physical examination she was of average built having plethoric face \& conjunctival injection. She had an overall dusky cyanotic complexion. Her pulse was $60 \mathrm{bpm}$, regular, BP was 250/110 mm of Hg. No other positive findings like hepato-splenomegaly or weakness of any part of the body were present. She had H/O admission on 1992 for accelerated hypertension. A provisional diagnosis of polycythemia rubra vera was made \& blood was sent for investigation.

Investigations revealed hemoglobin $17.50 \mathrm{gm} / \mathrm{dl}$ ( $\mathrm{N}-12$ to $16 \mathrm{gm} / \mathrm{dl}$ ), red cell count $8.91 \mathrm{million} / \mu \mathrm{l}(\mathrm{N}-3.5$ to $6 \mathrm{M} / \mu \mathrm{l})$, Hct. 58.50\% ( N-37 to 52\%), MCV 65.70fL (67 to $96 \mathrm{fL}$ ), MCH 19.60 pg ( N 27 to 32 pg), WBC $13.11 \mathrm{k} / \mu \mathrm{l}$ ( N150-450 $\mathrm{k} / \mu \mathrm{l}$ ) with ESR $02 \mathrm{~mm}$ in Ist hour. PBF showed erythrocytosis, thrombocytosis with microcytic hypochromic blood picture, leukocytosis. Her bilirubin level was upper limit of normal $(1.78 \mathrm{mg} / \mathrm{dl}$, range was .2 to $1.3 \mathrm{mg} / \mathrm{dl}$ ) \& uric acid level was $10.10 \mathrm{mg} / \mathrm{dl}$ (N-2.5 to 6.2 ).

High blood level of hemoglobin, PCV \& a raised platelet count with leukocytosis aroused the suspicion of PRV. Taking all the above parameters into account $\&$ in consultation with a hematologist she had undergone bonemarrow (Fig.-1) study which revealed 


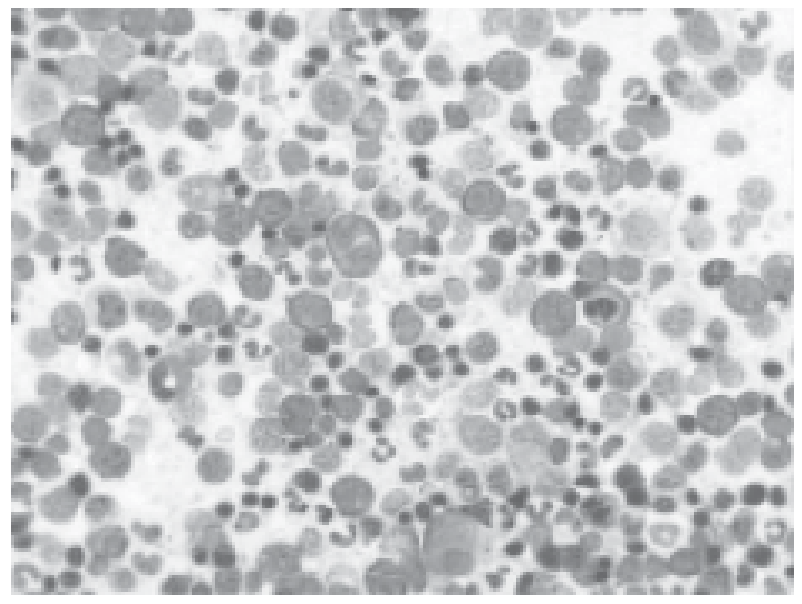

Fig-1: Bone marrow film demonstrating dominance of erythropoiesis

- hypercellular marrow with increased M:E ratio,

- erythropoiesis hyperactive \& micronormoblastic,

- granulopoiesis also hyperactive \& maturing into segmented form with few myelocytes,

- megakaryocytes - increased in number \& shows dysmegakaryopoiesis.

Non-contrast computed tomography of brain (CT scan) revealed consistent with left cerebral infarct \& white matter ischaemic changes \& USG of whole abdomen showed normal.

She was treated with phlebotomy twice (at an interval of 7 days), Tab Hydroxyurea (500 mg/day), Tab. Ecosprin (75mg/day), Tab Esloric , Beta-blocker, ACEI, Calcium channel blocker \& Proton pump inhibitor.

\section{Discussion:}

Polycythaemia rubra vera occurs in all age groups, ${ }^{10}$ one study found although the incidence increases with age, the median age at diagnosis to be 60 years. ${ }^{11}$ About a third presents with symptoms due to thrombosis. Three quarters of this is arterial thrombosis and a quarter is venous thrombosis. Features include stroke, MI, DVT and pulmonary embolism. Quantitative platelet derangement plays a role in the development of thrombosis and ischemia which leads to increased incidence of stroke, MI and arterial or venous thrombosis. ${ }^{12}$ Hypertension is common in patient with PRV. This case report outlines the investigation and management of a patient who developed a neurological syndrome due to PRV. The diagnostic workup includes hematological investigations and imaging studies, including CT. The management of this patient includes initial treatment of stroke \& hypertension. Further specific treatment should be directed towards the management of the hematological condition that is responsible for the neurological event. In the majority of the cases anti-platelet treatment will be appropriate with either aspirin ${ }^{13}$ or clopidogrel. ${ }^{14}$

The characteristics pathological processes of PRV, via cerebrovascular occlusion, could lead to TIA/stroke. In a patient of PRV, the management is only to prevent thrombotic complication \& to maintain normal haematocrit level by doing periodic phlebotomies. Hydroxyurea or Interferon- a or anegrilide can be given to control thrombocytosis. ${ }^{15}$

In our case the patient was diagnosed \& treated earlier, because of which she rescued from developing of frank feature of stroke. Hence any case presenting with TIA/ stroke like feature should always necessitate a thorough clinical, hematological \& radiological workup.

\section{References:}

1. Berk PD, Goldberg JD, Silverstein MN, Weinfeld A, Donovan $\mathrm{PB}$, Ellis JT, et al. Increased incidence of acute Leukaemia in Polucythaemia Vera associated with chloramphenicol therapy. N Engl J Med. 1981; 304:441-47.

2. “Treatment of Polycythaemia Vera by radio phosphorus or busulphan in randomized trail. Leukaemia and Hematosarcoma Cooperative Group, European Organization for Research on Treatment of Cancer (EORTC). Br J Cancer. 1981; 44: 7580 .

3. Najean Y, Mugnier P, Dresch C, Rain JD. Polycythaemia vera in young people: an analysis of 58 cases diagnosed before 40 years. Br J Haematol. 1987; 67: 285-91.

4. Zankovich R, Thiele J, Fiessler WD, Fischer R, Diehl V. Prognostic parameters in Polycythaemia rubra vera. Correlations of clinical and histomorphological features in 60 patients. Med Klin. 1987; 82: 889-94, 927.

5. Najean Y, Dresch C, Poirier O. Accidents Vasculaires dans la polyglobulie. [Vascular complications of polycythemia]. Ann Med Interne (Paris). 1983; 134: 390-94.

6. Berk PD, Goldberg JD, Donovan PB, Fruchtman SM, Berlin NI, Wasserman LR. Therapeutic recommendations in polycythemia vera based on Polycythemia Vera Study Group protocols. Semin Hematol.1986; 23: 132-43.

7. Spivak JL. Polycythaemia vera and myeloproliferative diseases, In: Brawnwald E, Hauser SL, Fausi AS, Casper DL, editors. Harrison's Principles of Internal Medicine. $15^{\text {th }}$ ed. New York: Mc Graw- Hill; 2001. p702-4.

8. Silverstein, A, Gilbert, H \& Wasserman, L. R. (1962). Neurological Complicvations of Polycythaemia, Annals of Internal Medicine, 57, 909.

9. Jacques Wallach; Interpretation of Diagnostic Test, $7^{\text {th }}$ Ed; Lippencott Williams \& Wilkins.

10. Berlin, NI.“Diagnosis \& Classification of Polycythaemias”. Semin Hematol 1975; 12: 339. 
11. Passamonti F, Malabarba L, Orlandi E, et al. ( 2003 ). “ Polycythaemia vera in young patients; a study on the long term risk of thrombosis, myelofibrosis \& Leukaemia.” Haematologica 88(1):13-8. PMID 12551821.

12. Schwarcz TH, Hogan LA, Endean ED, Roitman IT, Kazmers A, Hyde GL. Thromoembolic complication of polycythaemia: Polycythaemia Vera versus smokers' polycythaemia. J Vasc Surg. 1993; 17: 518-23.

13. Landolfi R, Marchioli R, Kutti J, et al. Efficacy \& safety of low dose aspirin in polycythemia vera. N Engl J Med 2004; 114-24.
14. Mosso M, Georgiadis D, Baumgartner RW. Progressive occlusive disease of large cerebral arteries \& ischaemic events in a patients with essential thrombocythemia. Neurc Res 2004;: 702-03.

15. Cognitive impairment in PRV: Partial Reversibility upon Lowering of the HAEMATOCRIT. Laura Di Pollina, Reinhild M, Anne-Claude J, Vander L, Jean-Pierre Michel, Gabriel G. Department of Geriatrics, University Hospital of Geneva, Switzerland. 